\title{
Technology and old age in Japan
}

Yasuyuki Gondo

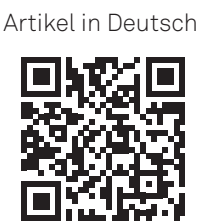

www.hgf.io
Article en français

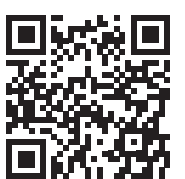

www.hgf.io
The population of older people has been increasing in the last few decades in Japan. This larger demographical shift provided new business opportunities to companies. Innovative technologies and services for older people have been developing. Some of these are already at work; further technological revolution seems to promise "successful" aging for the future super-aging society. This report provides an overview of technologies currently applied with older people and introduces some examples of new technologies developing in Japan.

\section{Technologie und Alter in Japan}

Der Anteil älterer Menschen an der Bevölkerung hat in den letzten Jahrzehnten in Japan zugenommen. Dieser signifikante demographische Wandel hat Unternehmen neue geschäftliche Möglichkeiten eröffnet. Speziell für ältere Menschen sind innovative Technologien und Dienstleistungen entwickelt worden, von denen einige bereits angewendet werden. Die weitere, zu erwartende technologische Revolution scheint für die künftige Gesellschaft mit

\section{Introduction}

Japan is a leading country in the progress of social aging (Muramatsu and Akiyama, 2011). Introducing Japan's experience might be a useful reference for other countries. Especially in the technology field, many operational services have already been introduced or are under development today. To address these issues, I divided technology for older people into three functional dimensions: compensation, communication, and health promotion. Here, compensation indicates assisting or regaining function through technology use such as hearing aids. Communication indicates bonding between people and enriching wellbeing. Health promotion indicates maintaining health through communication technology such as activity monitoring by smartwatches. extrem vielen alten Menschen ein «erfolgreiches» Altern zu versprechen. Dieser Bericht vermittelt einen Überblick über Technologien, die derzeit von älteren Menschen angewandt werden. Er stellt ferner einige Beispiele für neue Technologien vor, die in Japan entwickelt werden.

DOI 10.0124/2297-5160/a000018

\section{Technologie et âge avancé au Japon}

La population des personnes âgées a augmenté au cours des dernières décennies au Japon, une évolution démographique importante qui a fourni de nouvelles opportunités commerciales aux entreprises. Les technologies et services innovants pour les personnes âgées se sont développés et certains sont déjà en cours d'utilisation. De plus, la révolution technologique semble promettre à la future société super-vieillissante de « réussir » à bien vieillir. Le présent rapport fournit une vue d'ensemble des technologies actuellement appliquées auprès des personnes âgées et donne quelques exemples de nouvelles technologies qui se développent au Japon. DOI 10.1024/2297-5160/a000019

\section{Compensation technology}

A survey reported that Japanese older people complain about hearing problems at the same ratio as European older people do (about $10 \%$ ). However, hearing aids users are fewer (14\%) than in Western countries (24-41\%) (JapanTrak 2012). While in-the-ear and ear-fit type devices are not popular, other types of devices such as bone-conduction hearing aids and their application to bone-conduction telephones are becoming popular. Other unique machines have also been marketed. The most popular device is an extension speaker system for TVs, which enables older people to listen to TV sound nearby them without increasing TV loudness itself.

For broadcasting technology, a real-time speech rate conversion system, developed more than 10 years ago, might receive more focus in the future. This system was invented by the NHK Broadcasting Culture Research Insti- 
tute and radios equipped this mechanism were released (https://www.nhk.or.jp/strl/publica/bt/en/pr0013.pdf). This product literally fits with the requirements of the times. Core listeners of the midnight program broadcast by NHK have been older people since its beginning in 1989. Today, they have hired many retired DJs (average age of 64 years ranging from 49 to 74) and broadcast contents preferred by older listeners. This fact also indicates that latent demand for hearing compensation in older people is high. One major reason for not using hearing aids is discomfort from using poorly adjusted devices. More sophisticated and integrated services for hearing compensation are needed.

Assistive devices for mobility compensation are important for independent living. If one went shopping in Japanese downtowns, one would easily recognize older women wheeling rollators called "silver car". A variety of types with colorful decorations are sold in shops. Typical silver cars provide shopping cages and temporary benches for rest.

Power-operated vehicles are popular for frailer people. The first commercial products arrived in stores in the 1980s. Now two types of vehicles are sold: joystick and handle operation. Interestingly, shipping volume has declined since the peak year $2002(33,477)$ to $2014(19,438)$. One of the plausible explanations for lost popularity is the spreading concept of "use it or lose it" in Japan. Not only older people but also family members who are potential caregivers in Japan worry about increased function loss by depending on this convenient machine. Recently, wheelchairs combined with bicycle type pedals were released (http://www.starlinxpedalchair.com/history.html). The advantage of this vehicle is users' own leg motions are used to move, even when the user is sitting on the chair. More advanced technology robots, which rehabilitate lost function have been developed (http://www.cyberdyne.jp/ english/products/HAL/index.html). Providing minimum support for declining functioning would be a trend for future compensation technology.

For the purpose of short distance transfer outside residences, micro electric vehicles are leading candidates. Those vehicles have the advantages of low emissions and convenient use. Currently, however, a driver's license is required to use them. The national government began a new license renewal test for drivers aged 75 and older to prevent car accidents. Considering the main users of this vehicle, managing license approval will be a major problem. Implementation of automatic driving systems would be indispensable for future evolution.

\section{Communication}

Increasing numbers of older people living alone is also an issue in Japan. The Japanese government estimates 6.0 million older persons living alone in 2015, which is expect- ed to increase to 7.6 million in 2035. A TV documentary program broadcasted in 2005 on "kodoku shi", the death of a person who lives alone and dies at home without others noticing for a long period, had an impact on our society. The white paper on the aging society in 2015 reported that $45 \%$ of older people living alone do not feel "kodoku shi" is someone else's problem. A communication device that connects older people and family or society is believed to prevent social isolation and reduce "kodoku shi".

We have a long history of using technology for this issue. Emergency call systems targeted to older people were developed in the 1970s. This is an active type of communication system, informing of emergency conditions by using pendant-type wireless terminals or emergency buttons on the wall. In 2000, more than $95 \%$ local government supplied the service in some manner. However, several papers reported that the actual number of users was less than $10 \%$ of aged households; older individuals frequently hesitate to use this system even when they have it.

The "mimamori" (watch over) hotline system, which uses an electric jug to monitor older individuals' activities, began its first commercial service in 2001 combined with a product used in daily life. This service was developed by a vacuum bottle company (http://www.zojirushi-world. com/activities/amenities.html). This system monitors electric jug use in residents and enables monitoring older people through passive communication. Seeing older peoples' higher tendencies to hesitate to use active emergency communication, this passive communication was a brilliant idea at that time. Unfortunately, the number of users declined from 7,600 when it started to 3,600 today. The concept of passive communication survives and was inherited by more sophisticated devices such as monitoring electricity or city gas use, detecting motion, or biological information such as breathing detection sensors in the house.

Recently, prototypes of humanoid type communication robots implementing communication functions were released by various companies. They are planning to locate robots as core interfaces to total services from monitoring to health promotion. To date, because of reliability issues, monitoring and health promotion services provided through humanoid type robots are in a trial phase and are not sold in stores.

At present, the most commercially successful product in the communication dimension is the Paro. The Paro is a baby harp seal robot produced to implement healing and therapeutic effects (http://www.parorobots.com/). Although language communication is not possible, healing effects were scientifically proved. Many nursing homes in Japan and other countries have already begun using Paro, mainly for mental stabilization for demented people. Telenoid (http://www.geminoid.jp/projects/kibans/res/Telenoid-resources.html) is also a communication robot invented in Japan. Interestingly, demented people show intimacy with this unusual robot in the trial phase in Denmark. 


\section{Health promotion}

The health promotion dimension is a growing segment of technology not only for older people. This year, a large epidemiological study for dementia incidence started with the use of a wristband-type activity sensor with 1,000 older people. In this project, daily activity, sleep, and frequency of conversation monitored through wristbands and their correlation with brain amyloid beta levels will be studied (http://www.pcworld.com/article/2971792/gadgets/toshiba-rolls-out-activity-trackers-for-seniors.html).

In addition to innovative monitoring devices, common technologies have been reconsidered. Some years ago, the media reported that older people are becoming the majority at amusement centers (http://edition.cnn.com/2012/ 02/08/world/asia/japan-older-gamers). New older generations are more familiar with arcade and TV games than older generations. Game machine companies have been modifying arcade games for rehabilitation aid and health promotion. For example, "Drum Master" is a game to compare the correct timing of hitting drums in songs. Modified versions released in 2004 changed to songs more familiar to older people, added holding assistance mechanisms to sticks, made drum positions lower for wheel chairs, and adopted easier hit timing criteria. The same year, this company founded care service institutions equipping game machines. Today, different types of game machines for physical and mental training for older people are sold. These machines are expected to work as alternatives to rehabilitation workers and reduce cost for care and rehabilitation.

\section{Conclusion}

Over the last decades, many technologies for older people were developed and sold. Some still remain in use and continue transformation; some have lost popularity today. The author speculates three factors are keys to popularity: less annoying when use, minimum support not to lose function, and fit with the times. Older people evaluate benefits and risks to technology use very carefully. This year, a cellphone company started selling a humanoid type communication robot (http://www.softbank.jp/en/robot/) to consumers directly. As mentioned earlier, communication robots are expected to be a hub for multiple services provided for older people. The national government established Japan's Robot Strategy (http://www.meti.go.jp/english/press/2015/pdf/0123_01b.pdf) and strongly drives this technology forward for future industry. If all necessary needs, compensation, communication and health promotion will be integrated into robots, it will be a real technical revolution for a successful super aging society.

\section{References}

Muramatsu, N. \& Akiyama, H. (2011) Japan: Super-Aging Society Preparing for the Future. The Gerontologist, 51/4, 425-432.

Hougaard S., Ruf S. \& Egger C. (2013) EuroTrak + JapanTrak 2012: Societal and Personal Benefits of Hearing Rehabilitation with Hearing Aids - http://www.hearingreview.com/2013/03/euro trak-japantrak-2012-societal-and-personal-benefits-of-hea ring-rehabilitation-with-hearing-aids/\#sthash.9spe5nAY.dpuf

\section{Acknowledgement:}

English information accessible via internet was mainly cited for non-Japanese native readers. This article was supported a grant 263101040 from the Ministry of Education, Culture, Sports, Science, and Technology of Japan. Average age of radio DJs was provided by Miss Kazuko Yasumura.

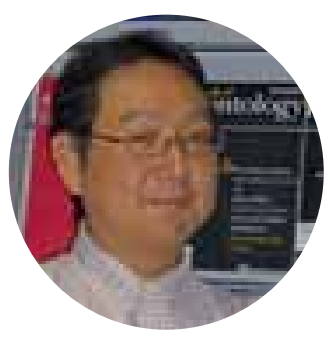

Prof. Dr. Yasuyuki Gondo is Associate Professor at Osaka University, Graduate School of Human Sciences and Clinical Thanatology and Geriatric Behavioral Science. ygondo@hus.osaka-u.ac.jp 